\title{
Characterising online museum users: a study of the National Museums Liverpool museum website
}

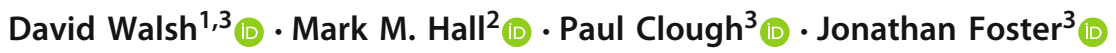 \\ Received: 5 February 2018 / Revised: 27 June 2018 / Accepted: 27 June 2018 / Published online: 5 July 2018 \\ (c) The Author(s) 2018
}

\begin{abstract}
Museums are increasing access to their collections and providing richer user experiences via web-based interfaces. However, they are seeing high numbers of users looking at only one or two pages within $10 \mathrm{~s}$ and then leaving. To reduce this rate, a better understanding of the type of user who visits a museum website is required. Existing models for museum website users tend to focus on groups that are readily accessible for study or provide little detail in their definitions of the groups. This paper presents the results of a large-scale user survey for the National Museums Liverpool museum website in which data on a wide range of user characteristics were collected regarding their current visit to provide a better understanding of their motivations, tasks, engagement and domain knowledge. Results show that the frequently understudied general public and non-professional users make up the majority (approximately 77\%) of the respondents.
\end{abstract}

Keywords Digital cultural heritage $\cdot$ Museum website $\cdot$ User research $\cdot$ User groups $\cdot$ Survey

\section{Introduction}

Museums have expanded their web-based offerings, providing not only access to general information about the museums, but also direct access to their holdings, digital collections and online exhibits. Various studies have explored the relationship between museums, their websites and visitors, especially how museum websites are used to connect visitors' pre- and post-visit activities to the physical museum [31]. The provision of web-based resources has opened up museums to wider and more diverse user groups and led to a significant rise in the number of visitors to museum websites

David Walsh

david.walsh@edgehill.ac.uk; dwalsh1@sheffield.ac.uk

Mark M. Hall

mark.hall@informatik.uni-halle.de

Paul Clough

p.d.clough@sheffield.ac.uk

Jonathan Foster

j.j.foster@ sheffield.ac.uk

1 Department of Computer Science, Edge Hill University, Ormskirk, Lancashire, UK

2 Institute of Computer Science, Martin-Luther-University Halle-Wittenberg, 06120 Halle, Germany

3 Information School, University of Sheffield, Sheffield, UK
[26]. However, museums have been struggling with large numbers (often more than 50\%) of users visiting their sites, looking at one or two pages, and then leaving within a very short period of time (generally less than $10 \mathrm{~s}$ ) [6,22]. To counteract this, many museums are taking an "audience-centric" approach to better understand their online visitors and recognise that multiple user types use the website differently [49].

Over the years, many studies have sought to determine the information behaviour of users with various demographics, domains, professions and roles [5,13]. Such studies have highlighted the diversity of users with respect to age, gender, personality, interests, expertise, profession, role, socio-economic background, motivation, intent and task. Understanding and categorising users can help to develop, adapt and evaluate information systems from the perspective of the user and their environment. For example, users with a lack of archival expertise may find formulating search request, interpreting and contextualising search results difficult [14]. Knowing this would allow specific search aids to be designed and implemented to support these users. Similarly, users from diverse backgrounds come to digital collections with varying goals, tasks and information needs [40]. A consequence of this is the wide variety of requirements that service providers and content creators have to consider when designing methods of information access $[26,44]$. Increasingly, cultural heritage services are being tai- 
lored to individuals and groups (i.e. via personalisation and adaptive systems) and therefore require some kind of differentiation between user groups [2]. As Skov \& Ingwersen [41, p.92] highlight: "Understanding online museum visitor behaviour is critical to the development of relevant and useful museum websites".

Where digital cultural heritage users have been studied in the past, however, the focus has primarily been on user groups that are easier to access, such as experts, researchers and museum staff. The general user and the non-professional user generally receive less attention; however, we hypothesise that the majority of users of museum websites come from these groups. Understanding them and how their needs and behaviours differ from the user groups that have been studied more frequently will enable museum websites to adapt their content and style of presentation to better support them. To this end, we present the first large-scale study of users from a major UK museum website: the National Museums Liverpool (NML). ${ }^{1} \mathrm{NML}$ is a collection of seven museums that cover a wide range of areas from art galleries to natural history and slavery. Similar to the studies previously cited, data from their transaction logs indicate that approximately $60 \%$ of their users leave within $10 \mathrm{~s}$. They thus form an appropriate case study, mainly as their wide spread of subject areas leads to varying museum visitors. Within this context, the study addresses the following research questions:

RQ1: Which are the most frequent user groups of NML's website?

RQ2: What characteristics distinguish the "general public" and "non-professional" groups?

RQ3: What characterises the interactions of the "general public" and "non-professional" groups with NML's website?

The remainder of this paper is structured as follows: in Sect. 2, we discuss existing work to understand and classify digital cultural heritage users; Sect. 3 describes the study we undertook; Sect. 4 presents results, which are discussed in Sect. 5; and Sect. 6 presents our conclusions and directions for future work.

\section{Literature review}

\subsection{User interactions with museum websites}

One of the first studies undertaken regarding visitors to physical museums was conducted in 1884 in Liverpool Museum. Four groups of users: students, observers, loungers, and German and Scandinavian immigrants were identified [23].

\footnotetext{
${ }^{1} \mathrm{http}: / /$ www.liverpoolmuseums.org.uk.
}

Following on from this, studies have investigated museum visitors in various contexts, including their motivations [17], who they visited with $[12,42]$, the role adopted during their visit [17] and their engagement with the museum [46]. Engagement with cultural heritage is no longer just about the physical visit, but rather the entire visitor experience that starts online before the actual visit and ends after the visit has taken place [11,31]. Often the most common reason for visiting a museum website is to plan an upcoming visit to the physical museum $[3,31,49]$. Engagement with a museum can also be via online collections or websites, without any physical visit [38]. While it is tempting to apply physical visitor models to the digital world, there is no certainty that the two entirely overlap [10], and online visitors should, therefore, be studied in their own context $[32,35]$.

Studies of museum website visitors have evolved over time to go beyond merely using demographics to considering people's motivations and goals. For example, Falk [17] used qualitative data to show that demographic characteristics and factors, such as time of year, were not enough to truly understand and predict visitor behaviour. He identified five user groups based on users' needs: Explorers — motivated by personal curiosity, Facilitators - motivated by other people and their needs (i.e. a parent bringing a child), Experience Seekers - motivated by the desire to see and experience a place (i.e. tourists), Professional/Hobbyists - motivated by specific knowledge-related goals (i.e. a scholar researching a specific topic) and Rechargers - motivated by a desire for a contemplative or restorative experience [17]. Fantoni et al. [18] adopted Falk's motivational perspective and described five reasons for users engaging with the Indianapolis Museum of Art (IMA) website: (i) plan a visit to the museum; (ii) find specific information for research or professional purposes; (iii) find specific information for personal interest; (iv) engage in casual browsing without looking for something specific; and (v) make a transaction on the website. More recently, Villaespesa and Stack [49] utilise audiencecentric research to define online visitors to the Tate UK website and use techniques from audience segmentation to classify website visits based primarily on the motivations driving users to the site. These include: personal interest research, student research, professional research, inspiration, enjoyment, art news, repeat visit planning, first visit planning and organisational information. As the segmentation is primarily based on motivation, the same user can be in one type of visit mode on one visit to the website and be in a different one on another visit.

\subsection{Categories of user in cultural heritage}

Users' expertise is one of the most common facets for distinguishing between different types of user. The simplest distinction is between generic groups, such as novice and 
expert [26]. Vilar et al. [47, p.150] define professional users as those who act within the formal part of a profession, having good knowledge of the task, being trained and usually having experience with it and deep understanding of its context. More generally, Pantano et al. [34] define experts as specialists in the field of cultural heritage, while Marty [30] introduces the Museum Information Professional as someone working with information resources and a desire for meeting user needs whether users are inside or outside the museum.

In contrast to experts/professionals, the lay user, nonexpert, or novice are typified as having no formal or only limited training $[25,47]$ in relation to cultural heritage, or as being completely new to the entire environment [34]. Cifter \& Dong [7] list "knowledge of the task, information needs and system expectations" as the main distinction from the expert. Between these two extremes lies the hobbyist or non-professional user $[15,27,39,40,42]$ who shares with the expert the knowledge of cultural heritage, but has the lay user's focus on personal reasons. Related to both the novice and hobbyist are the casual leisure users who are often "firstand short-time visitors" [2, p. 74], who have "just stumbled across [the digital] collection in the same way that they would wander into the cultural heritage institution's physical space" [50, p. 1].

An analysis of the London Science Museum's physical and virtual visitors defined three groups based on their information needs [3]: general visitors who require general information, such as opening hours or prices; educational visitors who require additional, detailed information to plan their visit; and specialist visitors who need more detailed information on collections and offer more expertise. Similarly, Marchionini et al. [29] describe users from the Library of Congress National Digital Library: groups were defined by combining their motivations, domain knowledge, system knowledge, task focus and time allocation. This leads to nine different groups: staff, hobbyists, scholars, professional researchers, rummagers (browsers), object seekers, surfers, Teachers K-16, Students K-16. Similarly, the CULTURA project identified the following groups: professional researchers, apprentice investigators, informed users and the general public [44]. This latter group is of particular interest as "the primary audience of virtually all the sites is the general public, a grouping so heterogeneous that it provides little guidance regarding the design of the site" [24, p. 131].

However, user groups from previous research have been described in very little detail, usually based on one factor, such as motivation, task, technical knowledge, cultural heritage knowledge, domain knowledge or demographics, often resulting in nothing more than a descriptive sentence or two for the identified user groups [51]. In this paper, we investigate the range of users interacting with the NML website based on the multiple factors previously mentioned to better understand how these connect or vary according to the type of user, especially the general public and non-professional groups, which have received less attention.

\section{Methodology}

\subsection{Data collection}

To gather data from a range of visitors to the NML's website, we administered an online questionnaire using the PollDaddy system. $^{2}$ Participants were recruited via an intercept popup that was displayed on all pages of the museum website. The survey was offered to all website users and takes the form of a probability sampling approach. The pop-up had a delay of $10 \mathrm{~s}$ before it is showed to the user and only showed if they had not attempted the survey previously, or selected that they were not interested in participating. The online survey consisted of 21 questions and was piloted with eight experienced researchers and museum professionals. Amendments were made based on their feedback. The final questionnaire included a set of closed multi-choice pre-coded questions, with some questions providing an open-ended "other" response.

The decision to use an intercept pop-up over an instant or exit pop-up survey was primarily to capture a potentially wider audience during their initial interactions with the website [1]; their interest freshly aroused as opposed to an "instant pop-up" which can be perceived as aggressively interfering with the user's valuable time and content consumption, or the "exit pop-up" which can often be skipped or seen as a nuisance by users who think they have left the site. Even though the potential audience is international, the questionnaire was presented only in English as the NML website exists in English only and we assume potential participants would have sufficient English skills. Although we wanted to use an online survey to gather responses from a large number of users from across the site, we acknowledge its limitations: for example, the difficulty in acquiring a representative or random sample of visitors and often low response rates (Fig. 1).

The survey comprised six questions to gather demographic data (age, gender, education, employment status); the remaining questions were derived from the user group definitions and the studies identified in the literature discussed above. These were grouped into seven categories around aspects previously used to define groups: motivation [42], task [16,21,39,43], content types, sharing [21], engagement $[16,37,45]$, domain knowledge [39], usage [28] and technical expertise [45]. In the survey, visitors first had to confirm that they agreed to participate. They then answered the 14 questions focusing on the aspects defining user groups, before providing demographics data. Finally, on the last page, they

\footnotetext{
${ }^{2}$ https://polldaddy.com/.
} 


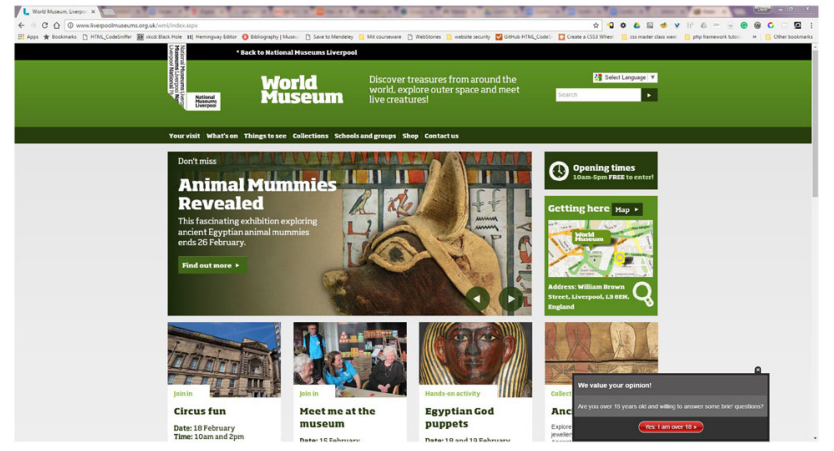

Fig. 1 Pop-up intercept used to invite participants to the study

are self-classified into a set of user groups identified from the literature. Participants were then thanked and provided with a link back to the NML site. Table 1 shows those questions where significant differences between the "general public", "non-professional" and other user groups were found.

The survey was available during a two-week period (1 February 2017 to 14 February 2017) on the museum-focused areas (World Museum, ${ }^{3}$ International Slavery Museum, ${ }^{4}$ Sudley House, ${ }^{5}$ and the Maritime Museum ${ }^{6}$ ) and a further two-week period (15 February 2017 to 1 March 2017) on the Gallery areas (Walker Art Gallery ${ }^{7}$ and Lady Lever Art Gallery $^{8}$ ). The reason they were not run simultaneously is that the Galleries had just run their own survey and we did not wish to affect the survey response rate due to survey fatigue [36], so a two-week gap was left before our survey went live.

\subsection{Participants}

Participants were recruited from visitors to the NML website. They were only invited once, regardless of whether they chose to participate in or ignore the pop-up. In total, 1118 participants were recruited, of whom 573 fully completed the survey ( $51 \%$ completion rate). Of these, nine were aged below 18 and subsequently filtered out, resulting in a final data set of 564 participants.

The demographics of the respondents are as follows: 343 $(61 \%)$ were female, $209(37 \%)$ male and 12 unspecified. The majority of participants $(204,36 \%)$ were in the $35-54$ age group, 147 (26\%) between 55 and 64, $110(20 \%)$ between 18 and 34, $84(15 \%)$ between 65 and 74 and $19(3 \%)$ over 75.61 (11\%) were educated to secondary school level, 134 (24\%) to

\footnotetext{
3 www.liverpoolmuseums.org.uk/wml.

${ }^{4}$ www.liverpoolmuseums.org.uk/ism.

5 www.liverpoolmuseums.org.uk/sudley.

${ }^{6}$ www.liverpoolmuseums.org.uk/maritime.

7 http://www.liverpoolmuseums.org.uk/walker.

${ }^{8}$ http://www.liverpoolmuseums.org.uk/ladylever/.
}

further education level, 193 (34\%) had a degree, $116(21 \%)$ had a masters-level qualification and $33(6 \%)$ held a doctoral qualification, 27 (4\%) participants chose no standard qualifications. Additionally, 170 of the participants held a professional certification. The majority (56\%) of participants were employed, either full-time $(208,37 \%)$ or part-time (107, $19 \%) .122(22 \%)$ were retired, $56(10 \%)$ students, and the remainder not in employment $(71,12 \%)$. Participants came from worldwide: 196 (35\%) from the Liverpool/Merseyside area, 129 (23\%) from the north-west of England, 102 (18\%) from the rest of England, 35 (6\%) from the rest of the UK and $102(18 \%)$ from the rest of the world. The majority of participants accessed the NML website using a desktop computer $(290,56.4 \%)$, with the remainder using a mobile phone $(19.8 \%)$ or tablet device $(23.7 \%)$.

\subsection{Data validation}

Participation in the survey was a self-selection process and to assess whether there were any significant biases in the participants. We compare the participant demographics to those reported by Google Analytics (GA) for NML's websites for the same period. Table 2(a) shows that the gender distribution is very similar between the survey participants and GA users. For the age distribution in Table 2(b), fewer of the GA users in the 18-34 bracket completed the survey, while more of the $55+$ GA users participated. This shift is to be expected, as the older users are more likely to have the time available to complete the survey. At the same time, the 18-34 bracket still makes up a significant fraction of the survey respondents; thus, we do not believe that the impact is significant. For the user location, there is also a shift with fewer non-UK users participating in the survey than generally visiting NML's websites. We believe that this is in part due to second-language English speakers being significantly less likely to take a survey on an English-language website. Similarly, the survey responses contain a higher fraction of users who identify as being from Merseyside (UK), most likely due to a potentially stronger connection with the museum and thus an increased likelihood of wishing to give back to the museum through the survey. At the same time, as the results will show, the responses to all questions show a widespread consensus. It is thus unlikely that the slight shifts in the participant demographics significantly impacted the response distributions.

The survey system also captured which page the users were visiting when they started the survey. Table 3 shows that participants were recruited from all six of NML's museums and galleries websites in significant numbers. The sample closely resembles the distribution of visitors to the physical 
Table 1 Survey questions that show significant differences between the "general public", "non-professional" and other user groups. Question \#7 allowed the participant to select multiple responses

\begin{tabular}{|c|c|c|}
\hline$\#$ & Category & Question \\
\hline 1 & Motivation & Today I am visiting the NML website: [personal, study, pass time, work] \\
\hline 2 & Visit Purpose & $\begin{array}{l}\text { What is the primary purpose of your visit to the NML website today? [Gain knowledge of a specific } \\
\text { museum object (a certain clock (The Barry astronomical clock) or statue (Huskisson Statue) for } \\
\text { example), Gain knowledge of a specific type of object (Egyptian burial objects), Gain general } \\
\text { knowledge of a collection (our art collection, the Egyptian or horology collection), Gain knowledge of } \\
\text { the collections that the museums exhibit, Prepare for a visit to the museum, To buy an item from the } \\
\text { online gift shop, To keep up to date with the museums news via the blogs, I don't know] }\end{array}$ \\
\hline 3 & Engagement & $\begin{array}{l}\text { How frequently do you visit the NML website? [This is my first time, a couple of times a year, monthly, } \\
\text { weekly, daily] }\end{array}$ \\
\hline 4 & Domain Knowledge & $\begin{array}{l}\text { In the context of cultural heritage and your current visit to the NML website please select the appropriate } \\
\text { statement: [novice, some experience, highly experienced, don't know] }\end{array}$ \\
\hline 5 & CH Knowledge & Rate your general Cultural Heritage knowledge $[1=$ low $-5=$ high $]$ \\
\hline 6 & Location & Where in the world are you at the moment? [World, UK, England, Northwest, Merseyside] \\
\hline 7 & User Group & $\begin{array}{l}\text { Which of the following groups would you place yourself in for this visit to the NML website? } \\
\text { [Non-professional researcher (hobbyist, amateur historian), Professional researcher (historian, } \\
\text { genealogist), Academic (Scholar, PostDoc researcher, academic support), Teacher, Student (college, } \\
\text { university, further education), Museum Staff (curator, archivist), General public/user] }\end{array}$ \\
\hline
\end{tabular}

Table 2 Comparison of the demographics between the survey participants (Survey) and the Google Analytics (GA) data

\begin{tabular}{lcc}
\hline & Survey $(\%)$ & GA $(\%)$ \\
\hline $\begin{array}{l}\text { (a) Gender } \\
\text { Male }\end{array}$ & 37 & 41 \\
Female & 61 & 59 \\
(b) Age & & \\
18-34 & 20 & 39 \\
$35-54$ & 36 & 37 \\
55-64 & 26 & 13 \\
65+ & 18 & 11 \\
(c) Location & & \\
World & 18 & 33 \\
UK & 82 & 67 \\
England & 92 & 92 \\
UK other & 8 & 8 \\
Merseyside & 35 & 25 \\
England other & 65 & 75 \\
\hline
\end{tabular}

In Table (c), the distribution "England/UK Other" is for those users who in the initial classification are classified as "UK", likewise for "Merseyside/England Other" from the "England" users

museums in 2017. ${ }^{9}$ This, together with the wide range of content the individual museums and galleries hold, provides high confidence that the results will generalise more widely to the websites of any museum or gallery that also has a physical presence.

\footnotetext{
9 http://www.liverpoolmuseums.org.uk/about/corporate/visitorinformation/.
}

\subsection{Data preprocessing}

In the survey, participants were asked to self-classify into one or more of seven groups or provided a free-text "other" response. In total, there were 39 different combinations of user group selections, of which Table 4 shows the ten most frequently selected responses, which cover $90 \%$ of the participant responses (509 participants). The remaining 10\% are covered by multiple-selection answers, where no individual set of responses covers more than six users. The majority of responses are for a single group only (450 participants, $80 \%$ ), strongly supporting the idea that most participants had clearly defined views on how the groups were delineated and where they saw themselves.

Before investigating the groups in more detail, the multiselection groups' responses were compared to their constituent groups' responses using Chi-square tests (e.g. "nonprofessional/general public" responses were compared to those of the "non-professional" and "general public" groups). Our hypothesis was that the multi-selection groups were due to uncertainty on the participants' interpretation of the group boundaries and that in their responses they would be equivalent to one of the constituent groups and distinct from the other(s). For the "non-professional/general public" group, there were significant differences to the "general public" group ( $p<0.05$ for all non-demographic questions) and no significant differences to the "non-professional" group. Likewise, the "academic/teacher" showed no differences from "academic", but differed from the "teacher" group $(p<0.05)$. For the "non-professional/teacher/general public" group, there were no differences to the "teacher" group, but significant differences $(p<0.05)$ to "non-professional" 
Table 3 Museum/Gallery pages the participants entered the survey from

\begin{tabular}{|c|c|c|c|c|c|c|}
\hline \multirow{3}{*}{$\begin{array}{l}\text { Landing } \\
2\end{array}$} & \multicolumn{4}{|l|}{ Museums } & \multicolumn{2}{|l|}{ Galleries } \\
\hline & \multicolumn{4}{|l|}{316} & \multicolumn{2}{|l|}{246} \\
\hline & ISM & Maritime & Sudley & WML & Lever & Walker \\
\hline Survey respondents & $71(.13)$ & $104(.19)$ & $23(.04)$ & $118(.21)$ & $47(.08)$ & $199(.35)$ \\
\hline 2017 physical visitor no's & $202,510(.16)$ & $450,989(.36)$ & $22,024(.02)$ & $344,186(.27)$ & $93,306(.07)$ & $139,245(.12)$ \\
\hline
\end{tabular}

ISM International Slavery Museum, Maritime Maritime Museum, Sudley Sudley House, WML World Museum, Lever Lady Lever Art Gallery, Walker Walker Art Gallery

and "general public" groups. These three multi-selection groups have thus been merged with the group they show no differences from, and the remaining analysis is conducted on the merged groups (see Table 4).

The multi-selection groups with less than six participants have not been processed in this manner, due to the group size being too small for statistical validity. Similarly, the "other" group has not yet been analysed in more detail and is not taken into account for the further analysis. The remaining analysis is thus conducted on the groups "General Public" (GP), "Non-professional" (NP), "Student" (S), "Teacher" (T), "Academic" (A) and "Museum Staff" (S).

\section{Results}

\subsection{RQ1: Which are the most frequent user groups of NML's website?}

Table 4 clearly validates our initial hypothesis that the "general public" and "non-professional" user groups represent a significant proportion of NML's online visitors. The largest group is the "general public" $(253,49.7 \%)$, making up almost half the users. Considering that in past studies the "general public" has often been characterised solely through the label, there is clearly a need to further define the "general public" and how they differ from the more frequently studied expert users. Similarly, while the "non-professional" group, who make up a further quarter of the participants, has seen more detail in their definition (as "hobbyists" or "amateur historians"), details in particular on how they distinguish from the "general public" are sparse.

\subsection{RQ2: What characteristics distinguish the "general public" and "non-professional" groups?}

To identify what distinguishes the "general public" and "nonprofessional" users from the other groups, for each question each groups' responses were compared to all other groups' responses using Chi-square tests. Based on this, the six
Table 4 Most frequently selected user groups, before applying the rules merging the multi-selection responses (pre-merging) and after (merged)

\begin{tabular}{lcl}
\hline Group & Pre-merging & Merged \\
\hline General Public & 253 & $253(.50)$ \\
Non-professional & 89 & $137(.27)$ \\
Non-professional/General Public & 48 & - \\
Student & 33 & $33(.06)$ \\
Other & 26 & $26(.05)$ \\
Teacher & 18 & $25(.05)$ \\
Academic & 16 & $25(.05)$ \\
Museum Staff & 10 & $10(.02)$ \\
Academic/Teacher & 9 & - \\
Non-professional/Teacher/General Public & 7 & - \\
\hline
\end{tabular}

In both cases the "Other" group has not been subjected to further analysis

questions listed in Table 1 were identified, ${ }^{10}$ which showed significant differences between the "general public" and "non-professional" groups and most of the other groups.

\subsubsection{Question \#1 (Motivation)}

Table 5 clearly shows that the main distinction is the focus on personal reasons for the visit (differences to all groups are significant at $p<0.001)$. Interestingly, there are a significant number of "general public" users who have visited the website purely to pass some time, often referred to as casual browsing $[33,50]$ and behaviour that is quite common in visits to the physical museum.

\subsubsection{Question \#2 (Visit Purpose)}

The visit purpose shows a slightly different picture (Table 6). Preparation for a visit is a major characteristic for both the "general public" and the "non-professional" groups. This is in line with the findings of previous studies as the most frequently mentioned motivation for visiting a museum website $[3,21,31]$. However, here the "general public" group is

\footnotetext{
10 The table also contains the question used by participants to selfcategorise.
} 
Table 5 Responses to question \#1 "Today I am visiting the NML website:"

\begin{tabular}{lllll}
\hline & Personal & Pass time & Study & Work \\
\hline General Public & $\mathbf{2 0 0}(. \mathbf{7 9})$ & $\mathbf{4 3}(. \mathbf{1 7})$ & $6(.02)$ & $4(.02)$ \\
Non-professional & $\mathbf{1 1 2}(.81)$ & $15(.11)$ & $5(.04)$ & $5(.04)$ \\
Student & $7(.21)$ & $2(.06)$ & $\mathbf{2 3}(.70)$ & $1(.03)$ \\
Academic & $8(.32)$ & $1(.04)$ & $\mathbf{9 ( . 3 6 )}$ & $\mathbf{7 ( . 2 8 )}$ \\
Teacher & $11(.44)$ & $4(.16)$ & $2(.08)$ & $8(.32)$ \\
Museum Staff & $2(.20)$ & $2(.20)$ & $0(.00)$ & $\mathbf{6}(.60)$ \\
Total & $340(.70)$ & $67(.14)$ & $45(.09)$ & $31(.07)$ \\
\hline
\end{tabular}

significantly different to both the "academic" ( $p<0.001$, $\left.\chi^{2}=41.3, d f=8\right)$ and "museum staff" ( $p=0.04$, $\left.\chi^{2}=16.5, d f=7\right)$ groups, but the "non-professional" group is only significantly different $\left(p=0.03, \chi^{2}=16.7\right.$, $d f=8)$ to the "academic" group. In fact, the "teacher" group is almost identical in its purpose to the "general public" group. At the same time, there is a significant difference $\left(p<0.001, \chi^{2}=32.1, d f=7\right)$ between the "general public" and "non-professional" groups.

\subsubsection{Question \#3 (Frequency of Visit)}

The frequency of visit shows a similar picture (Table 7), with significant differences between the "general public"/"nonprofessional" and the "academic" and "museum staff" groups ( $p<0.001)$, but no significant differences to the "teacher" and "student" groups.

\subsubsection{Question \#4 (Domain Knowledge)}

The level of domain knowledge differs from previous questions where the "general public" and "non-profes-sional" groups have been similar, as for domain knowledge there are some differences between the two (Table 8). For the domain knowledge about NML (Table 8), the "general public" is significantly different to all other groups at $p<0.001$, except for the "student" group where there is no significant difference. On the other hand, the "non-professional" group is significantly different at $p<0.01$ to all groups including the "student" group and the "general public" group.

\subsubsection{Question \#5 (CH Knowledge)}

Specific $\mathrm{CH}$ knowledge shows the same pattern for the "general public" (Table 9), but here the "non-profes-sional" group is only significantly different from the "academic" and "museum staff" groups $(p<0.05)$. The difference to the "general public" is borderline, but not significant $(p=0.66)$.

\subsubsection{Question \#6 (Location)}

Participants' location shows some differences (Table 10). The "general public" is significantly different from the "academic" and "student" groups $(p<0.03)$, while the "non-professional" group also differs significantly from the "teacher" group ( $\left.p=0.05, \chi^{2}=8.83, d f=4\right)$. The difference clearly is that both the "general public" and "nonprofessional" groups are much more local than the other groups.

\subsection{RQ3: What characterises the interactions of the "general public" and "non-professional" groups with NML's website?}

As stated above, one of the limitations of past studies is that they have provided only very limited details on what characterises the individual user groups. We address this limitation for the "general public" and "non-professional" groups, by providing details on who the users are, what they have come to NML's website for, how they interact with the website, what their level of knowledge is and what content they are looking at. This will allow future research and website design to better address these users.

Table 6 Responses to question \#2 "What is the primary purpose of your visit to the NML website today?"

\begin{tabular}{llllllllll}
\hline & Pre-Visit & MO & CO & KC & KI & Shop & News & Unknown & Other \\
\hline General Public & $\mathbf{1 5 4}(.61)$ & $23(.09)$ & $13(.05)$ & $4(.02)$ & $8(.03)$ & $12(.05)$ & $1(.00)$ & $1(.00)$ & $37(.15)$ \\
Non-professional & $49(.35)$ & $17(.12)$ & $9(.07)$ & $5(.04)$ & $\mathbf{1 2 ( . 0 9 )}$ & $0(.00)$ & $7(.05)$ & $3(.02)$ & $35(.26)$ \\
Student & $11(.34)$ & $6(.18)$ & $6(.18)$ & $3(.09)$ & $1(.03)$ & $0(.00)$ & $0(.00)$ & $1(.03)$ & $5(.15)$ \\
Academic & $5(.20)$ & $0(.00)$ & $2(.08)$ & $3(.12)$ & $\mathbf{5}(.20)$ & $1(.04)$ & $1(.04)$ & $0(.00)$ & $\mathbf{8}(. \mathbf{3 2})$ \\
Teacher & $\mathbf{1 5 ( . 6 0 )}$ & $3(.12)$ & $1(.04)$ & $0(.00)$ & $1(.04)$ & $0(.00)$ & $2(.08)$ & $0(.00)$ & $3(.12)$ \\
Museum Staff & $4(.40)$ & $1(.10)$ & $1(.10)$ & $2(.20)$ & $0(.00)$ & $0(.00)$ & $0(.00)$ & $0(.00)$ & $2(.20)$ \\
Total & $238(.50)$ & $50(.11)$ & $32(.07)$ & $13(.03)$ & $27(.06)$ & $13(.03)$ & $5(.01)$ & $5(.01)$ & $90(.18)$ \\
\hline
\end{tabular}

$M O$ Museum Overview (gain an overview over the museums' content), $C O$ Collection Overview (gain an overview over a collection), $K C$ Known Collection (look at the content of a known collection), KI Known Item (look for a known item) 
Table 7 Responses to question \#3 "How frequently do you visit the NML website?"

Table 8 Responses to question \#4 "In the context of cultural heritage and your current visit to the NML website, please select the appropriate statement"
Table 9 Responses to question \#5 "Rate your general Cultural Heritage knowledge"

(Likert-like scale, 1-low, 5-high)

\begin{tabular}{llllll}
\hline & First visit & Yearly & Monthly & Weekly & Daily \\
\hline General Public & $\mathbf{1 3 3}(. \mathbf{5 3})$ & $\mathbf{8 2}(. \mathbf{3 2})$ & $32(.13)$ & $6(.02)$ & $0(.00)$ \\
Non-professional & $\mathbf{7 8}(\mathbf{. 5 7})$ & $\mathbf{4 0}(. \mathbf{2 9})$ & $13(.09)$ & $6(.05)$ & $0(.00)$ \\
Student & $22(.67)$ & $7(.21)$ & $2(.06)$ & $2(.06)$ & $0(.00)$ \\
Academic & $10(.40)$ & $10(.40)$ & $2(.08)$ & $1(.04)$ & $\mathbf{2}(. \mathbf{0 8})$ \\
Teacher & $11(.44)$ & $8(.32)$ & $3(.12)$ & $3(.12)$ & $0(.00)$ \\
Museum Staff & $0(.00)$ & $2(.20)$ & $5(.50)$ & $1(.10)$ & $\mathbf{2}(. \mathbf{2 0})$ \\
Total & $254(.52)$ & $149(.31)$ & $57(.12)$ & $19(.04)$ & $4(.01)$
\end{tabular}

\begin{tabular}{lllll}
\hline & Novice & Intermediate & Expert & Unknown \\
\hline General Public & $\mathbf{7 8}(. \mathbf{3 1})$ & $\mathbf{1 5 3}(. \mathbf{6 0})$ & $16(.07)$ & $6(.02)$ \\
Non-professional & $29(.21)$ & $\mathbf{9 8}(. \mathbf{7 2})$ & $10(.07)$ & $0(.00)$ \\
Student & $\mathbf{1 4}(. \mathbf{4 3})$ & $\mathbf{1 5}(. \mathbf{4 5})$ & $3(.09)$ & $1(.03)$ \\
Academic & $0(.00)$ & $10(.40)$ & $\mathbf{1 5}(.60)$ & $0(.00)$ \\
Teacher & $5(.20)$ & $10(.40)$ & $8(.32)$ & $2(.08)$ \\
Museum Staff & $0(.00)$ & $5(.50)$ & $5(.50)$ & $0(.00)$ \\
Total & $126(.26)$ & $291(.60)$ & $57(.12)$ & $9(.02)$ \\
\hline
\end{tabular}

\begin{tabular}{llllll}
\hline & Low & & & High \\
\cline { 2 - 5 } & 1 & 2 & 3 & 4 & 5 \\
\hline General Public & $8(.03)$ & $\mathbf{4 7}(. \mathbf{1 9})$ & $\mathbf{1 1 2}(.44)$ & $\mathbf{7 0}(. \mathbf{2 8})$ & $16(.06)$ \\
Non-professional & $3(.02)$ & $\mathbf{1 4}(.10)$ & $\mathbf{5 6}(. \mathbf{4 1})$ & $\mathbf{4 9}(.36)$ & $15(.11)$ \\
Student & $1(.03)$ & $7(.21)$ & $15(.46)$ & $7(.21)$ & $3(.09)$ \\
Academic & $1(.04)$ & $0(.00)$ & $2(.08)$ & $\mathbf{1 0}(. \mathbf{4 0})$ & $\mathbf{1 2}(. \mathbf{4 8})$ \\
Teacher & $0(.00)$ & $1(.04)$ & $11(.44)$ & $6(.24)$ & $7(.28)$ \\
Museum Staff & $0(.00)$ & $0(.00)$ & $1(.10)$ & $\mathbf{5}(. \mathbf{5 0})$ & $\mathbf{4}(.40)$ \\
Total & $13(.03)$ & $69(.14)$ & $197(.41)$ & $147(.30)$ & $57(.12)$ \\
\hline
\end{tabular}

\subsubsection{Who are they?}

Tables 11 and 12 show the distribution of age and gender for "general public" and "non-professional" groups. The "general public" group has a higher female membership (61\%), while for the "non-professional" group membership is relatively evenly split (52\% female, $46 \%$ male). The overall age distributions are similar for the two groups and show a relatively normal distribution of ages. However, for both groups, there is a significant gender factor in the age distributions. In both groups, female users are significantly more likely to be younger than male users ("general public" $-p=$ $0.04, \chi^{2}=9.95, d f=4$, "non-professional" $-p=0.004$, $\left.\chi^{2}=7.75, d f=4\right)$, with the effect being more pronounced
Table 10 Responses to Question \#6 "Where in the world are you at the moment?"

\begin{tabular}{llllll}
\hline Group & Merseyside & Northwest & England & UK & World \\
\hline General Public & $\mathbf{9 5}(.38)$ & $\mathbf{7 3}(. \mathbf{2 9})$ & $44(.17)$ & $18(.07)$ & $23(.09)$ \\
Non-Professionals & $\mathbf{4 7 ( . 3 4 )}$ & $\mathbf{3 0}(.23)$ & $25(.18)$ & $10(.07)$ & $25(.18)$ \\
Students & $\mathbf{8}(. \mathbf{2 4})$ & $\mathbf{8}(.24)$ & $7(.22)$ & $1(.03)$ & $\mathbf{9}(.27)$ \\
Academics & $4(.16)$ & $3(.12)$ & $4(.16)$ & $1(.04)$ & $\mathbf{1 3}(.52)$ \\
Teachers & $\mathbf{1 3 ( . 5 2 )}$ & $3(.12)$ & $4(.16)$ & $1(.04)$ & $4(.16)$ \\
Museum Staff & $\mathbf{8}(. \mathbf{8 0})$ & $1(.10)$ & $1(.10)$ & $0(.00)$ & $0(.00)$ \\
Total & $175(.36)$ & $118(.25)$ & $85(.18)$ & $31(.06)$ & $74(.15)$ \\
\hline
\end{tabular}


Table 11 Age/gender distribution for the "general public" group, highlighting that female users are generally slightly younger than male users

\begin{tabular}{llllll}
\hline & $18-34$ & $35-54$ & $55-64$ & $65-74$ & $75+$ \\
\hline Female & $21(.14)$ & $\mathbf{6 2}(.40)$ & $43(.28)$ & $25(.16)$ & $3(.02)$ \\
Male & $5(.05)$ & $31(.33)$ & $\mathbf{3 9}(.41)$ & $15(.16)$ & $5(.05)$ \\
Rather not say & $0(.00)$ & $1(.25)$ & $2(.50)$ & $0(.00)$ & $1(.25)$ \\
Total & $26(.10)$ & $94(.37)$ & $84(.33)$ & $40(.16)$ & $9(.04)$ \\
\hline
\end{tabular}

Table 12 Age/gender distribution for the "non-professional" group, highlighting that female users are generally slightly younger than male users

\begin{tabular}{llllll}
\hline & $18-34$ & $35-54$ & $55-64$ & $65-74$ & $75+$ \\
\hline Female & $\mathbf{1 7 ( . 2 4 )}$ & $\mathbf{2 7 ( . 3 8 )}$ & $14(.20)$ & $13(.18)$ & $0(.00)$ \\
Male & $6(.10)$ & $14(.22)$ & $\mathbf{2 2 ( . 3 5 )}$ & $\mathbf{1 7}(.27)$ & $4(.06)$ \\
Rather not say & $1(.33)$ & $1(.33)$ & $1(.33)$ & $0(.00)$ & $0(.00)$ \\
Total & $24(.17)$ & $42(.31)$ & $37(.27)$ & $30(.22)$ & $4(.03)$ \\
\hline
\end{tabular}

for the "non-professional" group. It is unclear why these differences exist and further study is needed to investigate this.

\subsubsection{What are they here for?}

The results in Table 5 clearly show that for the majority of both the "general public" and "non-professional" groups, their motivation is personal, which, as discussed earlier, distinguishes them from the other groups. What is more interesting from a research/design point of view are those "general public" users who have come simply to pass the time (17\% of "general public" users). How to support these users and what kind of features a museum website should have to enable "passing the time" is an open research question $[33,48]$.

While their motivations are similar, the kind of information that they are looking for differs significantly between the two groups, as discussed earlier. In Table 13, the four response options "museum overview", "collection overview", "known collection" and "known item" have been aggregated into a single "content" response to highlight this difference. The "general public" group is primarily interested in planning an upcoming visit $(61 \%)$, with some interest in what content is available (19\%). On the other hand for the "nonprofessional" group, pre-visit (36\%) and content information $(31 \%)$ needs are almost equivalent.

As stated above, the survey also captured the page users were viewing before they started the survey. These entry points where manually classified into the same aggregate categories, plus a category for those who started the survey from the landing page. The results are comparable to the survey results (see Table 5), but for those participants who came directly from the landing page it is impossible to determine which category they would visit. As with the survey responses, there is a significant difference ( $p<0.001$, $\chi^{2}=18.312, d f=3$ ) between the two groups, with the "non-professional" group more likely to come from content pages.

The entry points can also be used to show that both groups are drawn from all museums and galleries (see Table 14) and that there are no significant differences between the two groups. This also means that the characterisation for the two groups that we present here is likely to be applicable to a wide range of museums and galleries that have both a physical and online presence.

\subsubsection{What is their level of knowledge?}

The survey enquired about users' general $\mathrm{CH}$ knowledge and their specific CH knowledge about NML. As discussed earlier, the two groups are similar in their general $\mathrm{CH}$ knowledge (see Table 9), but the "non-professional" group indicates significantly higher specific $\mathrm{CH}$ knowledge about NML (see Table 8). The results also indicate that in general a basic level of $\mathrm{CH}$ knowledge can be assumed for both groups and that the number of complete novices lies somewhere between 20 and $30 \%$ (based on the fraction responding either 1 or 2 to the general $\mathrm{CH}$ knowledge and the fraction classifying themselves as novices in the specific $\mathrm{CH}$ knowledge question).

A further indication of the level of knowledge that can be expected is provided by the users' frequency of visit (see Table 7), where for both groups only $12-13 \%$ of the users visit the site more than once a year. Furthermore, over $50 \%$ of both groups were visiting the website for the first time. Familiarity with the layout of the websites and what is available cannot be assumed (Table 15).

\subsubsection{How do they interact?}

To characterise how users interacted with the website, four questions were used: "What type of device are you using for this visit to NML website?", "When seeking information on a website which method do you prefer?", "When using the search box to search for content that you do not find in the first set of results, do you?" and "When on a web-page about an object or collection do you typically?".

Table 16 shows that the PC is still the primary device for accessing museum websites, but that portable devices now make up half of the devices used. At the same time, assuming that only a small fraction of tablet users are outside of the home, visiting NML's website on the go is still a less common pattern.

Looking at users' preferred information-seeking methods, Table 17 shows that for both groups using navigational links is the preferred interaction method over search. A potential reason for this is that these groups' lower $\mathrm{CH}$ knowledge 
Table 13 Responses to question \#2 "What is the primary purpose of your visit to the NML website today?"

Table 14 Page categories that the users entered the survey from

Table 15 Museum the participants were visiting before they entered the survey

\begin{tabular}{lllllll}
\hline & Pre-visit & Content & Shop & News & Unknown & Other \\
\hline General public & $\mathbf{1 5 4}(\mathbf{. 6 1})$ & $48(.19)$ & $12(.05)$ & $1(.00)$ & $1(.00)$ & $37(.15)$ \\
Non-professional & $\mathbf{4 9 ( . 3 6 )}$ & $\mathbf{4 3 ( . 3 1 )}$ & $0(.00)$ & $7(.05)$ & $3(.02)$ & $35(.26)$ \\
\hline
\end{tabular}

Responses "museum overview", "collection overview", "known collection", and "known item" have been aggregated into a single "content" response

\begin{tabular}{llllllll}
\hline & Landing & Pre-visit & Content & Shop & News & Unknown & Other \\
\hline General public & $68(.27)$ & $\mathbf{1 0 8}(.43)$ & $74(.29)$ & $0(.00)$ & $0(.00)$ & $0(.00)$ & $3(.01)$ \\
Non-professional & $24(.17)$ & $42(.31)$ & $\mathbf{7 0 ( . 5 1 )}$ & $0(.00)$ & $0(.00)$ & $0(.00)$ & $1(.01)$ \\
\hline
\end{tabular}

The pages have been categorised using the same categories as participants saw in question \#2, with the addition of a "landing" category for those that entered the survey directly from NML's landing page

\begin{tabular}{lllllll}
\hline & ISM & Lever & Maritime & Sudley & Walker & WML \\
\hline General Public & $17(.07)$ & $24(.09)$ & $47(.19)$ & $13(.05)$ & $93(.37)$ & $59(.23)$ \\
Non-professional & $16(.12)$ & $13(.09)$ & $34(.25)$ & $7(.05)$ & $43(.31)$ & $24(.18)$ \\
\hline
\end{tabular}

ISM International Slavery Museum, Maritime Maritime Museum, Sudley Sudley House, WML World Museum, Lever Lady Lever Art Gallery, Walker Walker Art Gallery
Table 16 Responses to the question "What type of device are you using for this visit to NML website?"

\begin{tabular}{llll}
\hline & PC & Tablet & Phone \\
\hline General Public & $127(.50)$ & $72(.29)$ & $54(.21)$ \\
Non-professional & $77(.56)$ & $33(.24)$ & $27(.20)$ \\
\hline
\end{tabular}

Table 17 Responses to the question "When seeking information on a website which method do you prefer?"

\begin{tabular}{lll}
\hline & Search box & Navigation links \\
\hline General Public & $83(.33)$ & $170(.67)$ \\
Non-professional & $56(.41)$ & $81(.59)$ \\
\hline
\end{tabular}

means that they find it harder to formulate successful queries and are thus prefer the guided nature of navigational links.

The influence of $\mathrm{CH}$ knowledge on interactions with the search system is also visible in Table 18, which shows the groups' search use patterns. "Non-professional" users are significantly more likely ( $\left.p=0.02, \chi^{2}=7.418, d f=2\right)$ to persist with query reformulations until they successfully find what they are looking for. It is likely that their higher $\mathrm{CH}$ knowledge allows them to modify their searches to successfully retrieve the information they are looking for.

There are also significant differences between the two groups in how they interact with the content $(p=0.006$, $\chi^{2}=10.255, d f=2$ ). Table 19 shows that "nonprofessional" users are more likely to read all the information on a content page, while the "general public" group shows an increased preference for pictures and illustrations. Con-
Table 18 Responses to the question "When using the search box to search for content that you do not find in the first set of results, do you?"

\begin{tabular}{llll}
\hline & $\begin{array}{l}\text { Stop } \\
\text { searching }\end{array}$ & $\begin{array}{l}\text { Try a further } \\
\text { 2-3 queries }\end{array}$ & $\begin{array}{l}\text { Persist until } \\
\text { success }\end{array}$ \\
\hline General public & $24(.09)$ & $151(.60)$ & $78(.31)$ \\
Non-professional & $9(.07)$ & $67(.48)$ & $61(.45)$ \\
\hline
\end{tabular}

Table 19 Responses to the question "When on a web page about an object or collection do you typically?"

\begin{tabular}{llll}
\hline & $\begin{array}{l}\text { Read every- } \\
\text { thing }\end{array}$ & $\begin{array}{l}\text { Scan for rele- } \\
\text { vant words }\end{array}$ & $\begin{array}{l}\text { Pictures } \\
\text { first }\end{array}$ \\
\hline General public & $46(.18)$ & $115(.46)$ & $92(.36)$ \\
Non-professional & $41(.30)$ & $64(.47)$ & $32(.23)$ \\
\hline
\end{tabular}

sidering that the "non-professional" group is more likely to come with the intent of viewing museum content online, this shift is to be expected.

\section{Discussion}

The results clearly show that the "general public" and "nonprofessional" groups are the primary audience of NML's websites, validating our initial hypothesis. Users belonging to these two groups are also likely to represent a significant fraction of the users who bounce off the website, as $71 \%$ of participants who indicated they just viewed one page came from the "general public" and "non-professional" groups. A 
better understanding of the interaction patterns of these two groups has the potential to improve the bounce rate, as both content and interfaces can be adapted accordingly.

The differences between the two groups, and those groups that have been studied more frequently (academics, students, museum professionals), fall into two main categories: why they are visiting NML's website and how much cultural heritage $(\mathrm{CH})$ knowledge/experience they have. Additionally, location distinguishes users, with both groups more likely to be local to the museum's location.

Both the "general public" and the "non-professional" have a primarily personal reason for visiting NML. What is particularly interesting is that there is a significant fraction of the "general public", and a smaller subgroup within the "nonprofessionals" who are visiting the website purely to pass time. This is behaviour that is well known from the literature on physical museums; indeed, the first study in Liverpool Museum identified 'loungers' as a significant visitor group [23]. It is interesting to observe that this behaviour would also appear to translate into the digital world. This subgroup in particular could benefit from better access to the museum's online holdings through engaging interfaces and not requiring significant domain knowledge. This would also benefit the wider "non-professional" group, who have a strong interest in being able to access the museum's digital holdings, but for whom the use of current search-based systems can still present significant challenges.

The second main characteristics of these groups are lower levels of cultural heritage knowledge and expertise that may result in the need for more domain knowledge support in their interactions. Interestingly, while there is no difference between the two groups regarding their general $\mathrm{CH}$ knowledge levels, when asked about their specific visit to the NML website, the "general public" indicated a lower level of expertise than the "non-professionals". This ties in well with the stronger focus of the "non-professional" group on museum content, as coming for specific content, users are likely to be more knowledgeable about what they came for and the museum they visit. It is also supported by the responses to their search behaviour, where significantly more "non-professional" users reported that they would persist in searching until they found the information they were searching for. This indicates that they are more familiar with $\mathrm{CH}$ search systems and know that the desired information is often hidden deep in the search results, or that their increased $\mathrm{CH}$ knowledge means that they have the ability to develop more complex and numerous search terms to finally retrieve what they are looking for.

The findings of this survey would appear to challenge previous research in which the domain knowledge of the non-professionals and the experts was found to be similar $[15,27,39,40,42]$. Our results show that the non-professionals have closer levels of domain knowledge to the general pub- lic group as opposed to the experts. Potential reasons for this could be that participants misunderstood the wording of the groups, or it could be an indication that the grouping of users is in some way artificial and not as clearly distinguishable as we like to believe, especially when multiple factors are used to differentiate users.

One major question is how to operationalise the findings. Fundamentally, the increased knowledge of the groups and their characteristics may help with the design of information systems and services. For example, developing interface features that specifically focus on the characteristics of these groups, such as their need for more domain knowledge support and their preference for non-search-based interactions. At the same time, there is the possibility that interfaces can be adapted dynamically based on their interactions with the site. The more detailed characterisation, in particular the purpose of the visit (see Table 6), could be used to improve machine learning models that classify users from user-system interaction data (e.g. transaction $\log s$ ), which in turn could then be used to classify users on the fly, adapting guidance and interface features presented to the user. Methods from user modelling, personalisation and market segmentation may be applicable and worthy of further exploration $[2,4]$.

The other question is the degree to which the results generalise outside of NML. In particular, since studies of other digital libraries [8] do not show a comparably high fraction of "general public" or "non-professional" users. However, these studies have tended to focus on digital libraries that do not have a physical presence. Thus, we believe that while there is clearly a significant difference to these online-only sites, the range of museums and galleries that participants were drawn from and the correlation with NML's wider website visitor population mean that the results will generalise to most museums and galleries that also include a physical presence.

\section{Conclusions and future work}

The majority of research into the users of cultural heritage websites has focused on those user groups that are easier to access (e.g. "academics", "museum staff", "students", and "professionals"). However, as the results of the survey reported here show, they form only a small fraction of the total number of website visitors and it is the least studied user groups that form the majority of the audience. In our case, the main user groups are the "general public" and "non-professional" visitors, who make up around $76 \%$ of all visitors. Knowing that these are the two major user groups allows future research to develop a deeper understanding of these groups and the museum to focus their content and interfaces on them. 
In addition to identifying these as the main user groups, the survey data also allowed us to define those criteria (motivation, task, content preference, experience sharing, engagement, domain knowledge, technical expertise, usage and demographics such as age, education and location) that distinguish these two groups from the other groups and also the criteria (domain knowledge, location, task, search behaviour) that distinguish the two groups from each other. Using this information to assist the creation of personas $[9,20]$ that can drive both research and the development of novel interfaces.

Due to the lower degree to which these two groups have been studied, it is also highly likely that current digital cultural heritage website offerings are not as suitable for these groups as ideally desired. This would also explain why this type of website suffers such high bounce rates, as based on the survey results, those users who leave immediately are more likely to belong to the "general public" and "non-professional" user groups. More research on interfaces and search tools specifically aimed at users with no or low general $\mathrm{CH}$ knowledge/domain knowledge is clearly needed. In particular, this needs to focus on those users who are visiting a digital museum or gallery for the first time.

Given the findings, and approach, it is clear that the main factors differentiating the NML users and user groups-and potentially their engagement-are internal factors, such as motivation, domain and $\mathrm{CH}$ knowledge, and related to the latter, task. At the same time, there is clear evidence that external influences, such as locality and perhaps cultural group, are also playing a role in the interactions between the user groups and NML. This would suggest that future research attention, and service development, can usefully take account not only of the information needs and uses of these two main user groups-via value-added services, for example, that begin with the user and not with the collection [19] — but also how the user's experience, for example, how the user responds to the collection and its objects, is influenced by the social, cultural and contextual environment within which the intending visitor is embedded.

Acknowledgements We would like to thank National Museums Liverpool for giving us access to their users and allowing us to run the survey on their websites.

Open Access This article is distributed under the terms of the Creative Commons Attribution 4.0 International License (http://creativecomm ons.org/licenses/by/4.0/), which permits unrestricted use, distribution, and reproduction in any medium, provided you give appropriate credit to the original author(s) and the source, provide a link to the Creative Commons license, and indicate if changes were made.

\section{References}

1. Andrews, D., Nonnecke, B., Preece, J.: Electronic survey methodology: a case study in reaching hard-to-involve internet users. Int. J. Hum. Comput. Interact. 16(2), 185-210 (2003)

2. Ardissono, L., Kuflik, T., Petrelli, D.: Personalization in cultural heritage: the road travelled and the one ahead. User Model. User Adap. Interact. 22(1-2), 73-99 (2012). https://doi.org/10.1007/ s11257-011-9104-X

3. Booth, B.: Understanding the information needs of visitors to museums. Mus. Manag Curator. 17(2), 139-157 (1998)

4. Brida, J.G., Meleddu, M., Pulina, M.: Understanding museum visitors' experience: a comparative study. J. Cult. Herit. Manag. Sustain. Dev. 6(1), 47-71 (2016). https://doi.org/10.1108/JCHMSD07-2015-0025

5. Case, D.: Looking for information: a survey of research on information seeking, needs, and behavior. Libr. Inf. Sci. (2007)

6. Ciber: Europeana 2012-2013: usage and performance update. Tech. rep., CIBER Research (2013). http://ciber-research.eu/

7. Cifter A.S., Dong, H.: User characteristics: Professional vs. lay users (2009)

8. Clough, P., Hill, T., Paramita, M.L., Goodale, P.: Europeana: what users search for and why. In: Kamps, J., Tsakonas, G., Manolopoulos, Y., Iliadis, L., Karydis, I. (eds.) Research and Advanced Technology for Digital Libraries, pp. 207-219. Springer, Cham (2017)

9. Cooper, A., et al.: The inmates are running the asylum: [Why hightech products drive us crazy and how to restore the sanity]. Sams Indianapolis, IN, USA (2004)

10. Cunliffe, D., Kritou, E., Tudhope, D.: Usability evaluation for museum web sites. Mus. Manag. Curator. 19(3), 229-252 (2001)

11. Devine, C.: The museum digital experience: considering the visitor's journey. In: MWA2015: Museums and the Web Asia 2015 (2015). http://mwa2015.museumsandtheweb.com/paper/themuseum-digital-experience-considering-the-visitors-journey/

12. Dierking, L.D., Falk, J.H.: Family behavior and learning in informal science settings: a review of the research. Sci. Educ. 78(1), 57-72 (1994)

13. Dobreva, M., O'Dwyer, A., Feliciati, P.: User studies for digital library development. Facet, London (2012)

14. Duff, W.M., Monks-Leeson, E., Galey, A., et al.: Contexts built and found: a pilot study on the process of archival meaning-making. Arch. Sci. 12(1), 69-92 (2012)

15. Elsweiler, D., Wilson, M.L., Lunn, B.K.: Chapter 9 understanding casual-leisure information behaviour. New Dir. Inf. Behav. 1, 211241 (2011). (Library and Information Science, Volume 1) Emerald Group Publishing Limited

16. Europeana: Results of the Europeana user survey 2014Europeana professional. (2014) http://pro.europeana.eu/blogpost/ results-of-the-europeana-user-survey-2014. Accessed 14 March 2016

17. Falk, J.H.: Identity and the Museum Visitor Experience. Left Coast Press, London (2009)

18. Fantoni, S.F., Stein, R., Bowman, G.: Exploring the relationship between visitor motivation and engagement in online museum audiences. In: Museums and the Web (2012)

19. Foster, J., Clough, P.: Embedded, added, cocreated: revisiting the value of information in an age of data. J. Assoc. Inf. Sci. Technol. (2018). https://doi.org/10.1002/asi.23987

20. Gajendar, U., Johnson, C.: The inmates are still running the asylum: how to share a design vision with engineers. In: Design, User Experience, and Usability Theory, Methods, Tools and Practice, pp. 276-282 (2011)

21. Goldman, K.H., Schaller, D.T., Adventures, E.W., et al.: Exploring motivational factors and visitor satisfaction in on-line museum vis- 
its. In: Bearman, D., Trant, J. (eds.) Museums and the Web 2004. Citeseer (2004)

22. Hall, M.M., Clough, P.D., de Lacalle, O.L., Soroa, A., Agirre, E.: Enabling the discovery of digital cultural heritage objects through wikipedia. In: Proceedings of the 6th Workshop on Language Technology for Cultural Heritage, Social Sciences, and Humanities, Association for Computational Linguistics, pp 94-100 (2012)

23. Hein, G.E.: Learning in the Museum, vol 47. Citeseer (1998) http:// books.google.com/books?id=Yz4pflj1jMoC\&pgis=1

24. Hertzum, M.: A review of museum web sites: in search of usercentred design. Arch. Mus. Inform. 12(2), 127-138 (1999)

25. Hogg, C., Williamson, C.: Whose interests do lay people represent? towards an understanding of the role of lay people as members of committees. Health Expect. 4(1), 2-9 (2001)

26. Johnson, A.: Users, use and context: supporting interaction between users and digital archives. What Are Archives? Cultural and Theoretical Perspectives: A Reader, pp. 145-64 (2008)

27. Kelly, L.: The interrelationships between adult museum visitors' learning identities and their museum experiences. chapter 3. Methodology, pp. 3-46 (2007). https://doi.org/10.1139/X11-042

28. Lapatovska, I., O’Brien, H.L., Rieh, S.Y., Wildemuth, B.: Capturing the complexity of information interactions: measurement and evaluation issues. In: Proceedings of the ASIST Annual Meeting, vol. 48 (2011). https://doi.org/10.1002/meet.2011.14504801057

29. Marchionini, G., Plaisant, C., Komlodi, A.: The people in digital libraries: multifaceted approaches to assessing needs and impact, Digital library use: Social practice in design and evaluation, pp. 119-160 (2003)

30. Marty, P.F.: Meeting user needs in the modern museum: profiles of the new museum information professional. Libr. Inf. Sci. Res. 28(1), 128-144 (2006)

31. Marty, P.F.: Museum websites and museum visitors: before and after the museum visit. Mus. Manag. Curator. 22(4), 337-360 (2007)

32. Marty, P.F.: Museum websites and museum visitors: digital museum resources and their use. Mus. Manag. Curator. 23(1), 8199 (2008)

33. Mayr, E., Federico, P., Miksch, S., Schreder, G., Smuc, M., Windhager, F.: Visualization of cultural heritage data for casual users. In: IEEE VIS Workshop on Visualization for the Digital Humanities (2016). http://publik.tuwien.ac.at/files/PubDat_250950.pdf

34. Pantano, E.: Virtual cultural heritage consumption: a $3 \mathrm{~d}$ learning experience. Int. J. Technol. Enhanc. Learn. 3(5), 482-495 (2011)

35. Peacock, D., Brownbill, J.: Audiences, visitors, users: reconceptualising users of museum on-line content and services. In: Museums and the Web, Citeseer (2007)

36. Porter, S.R., Whitcomb, M.E., Weitzer, W.H.: Multiple surveys of students and survey fatigue. New Dir. Inst. Res. 2004(121), 63-73 (2004)

37. Russell-Rose, T., Tate, T.: Designing the search experience: The information architecture of discovery. Newnes (2012)

38. Schweibenz, W.: Virtual museums. The development of virtual museums. ICOM News Magazine 3(3) (2004)

39. Skov, M.: The reinvented museum: exploring information seeking behaviour in a digital museum context. $\mathrm{PhD}$ thesis, Københavns Universitet'Københavns Universitet', Faculty of Humanities, School of Library and Information Science, Royal School of Library and Information Science, unpublished thesis (2009)
40. Skov, M., Ingwersen, P.: Exploring information seeking behaviour in a digital museum context. In: Proceedings of the Second International Symposium on Information Interaction in Context, IIiX'08. ACM, New York, NY, USA, pp. 110-115 (2008). https://doi.org/ $10.1145 / 1414694.1414719$

41. Skov, M., Ingwersen, P.: Museum web search behavior of special interest visitors. Libr. Inf. Sci. Res. 36(2), 91-98 (2014)

42. Spellerberg, M., Granata, E., Wambold, S.: Visitor-first, mobilefirst: designing a visitor-centric mobile experience. In: Museums and the Web (2016). http://mw2016.museumsandtheweb.com/ paper/visitor-first-mobile-first-designing-a-visitor-centricmobile-experience/

43. Stiller, J.: From curation to collaboration. PhD thesis, HumboldtUniversität zu Berlin, Philosophische Fakultät I (2014)

44. Sweetnam, M., Siochru, M., Agosti, M., Manfioletti, M., Orio, N., Ponchia, C.: Stereotype or spectrum: designing for a user continuum. In: The Proceedings of the First Workshop on the Exploration, Navigation and Retrieval of Information in Cultural Heritage, ENRICH (2013)

45. Taylor, E.: The national archive, UK government web archive discovery project: user survey, an unpublished technical report (2015)

46. Templeton, C.A.: Museum visitor engagement through resonant, rich and interactive experiences (2011). http://repository.cmu.edu/ theses/16

47. Vilar, P., Šauperl, A.: Archival literacy: different users, different information needs, behaviour and skills. In: Information Literacy. Lifelong Learning and Digital Citizenship in the 21st Century, Springer, pp. 149-159 (2014)

48. Villa, R., Clough, P.D., Hall, M.M., Rutter, S.A.: Search or browse? Casual information access to a cultural heritage collection. In: EuroHCIR, Citeseer, vol. 1033, pp. 19-22 (2013)

49. Villaespesa, E., Tate, U., Stack, J.: Finding the motivation behind a click: definition and implementation of a website audience segmentation. In: Museums and the Web 2015: Proceedings (2015)

50. Walsh, D., Hall, M.: Just looking around: Supporting casual users initial encounters with digital cultural heritage. In: Gade M, Hall M, Huurdeman H, Kamps J, Koolen M, Skov M, Toms E, Walsh D (eds.) Proceedings of the First International Workshop on Supporting Complex Search Tasks co-located with the 37th European Conference on Information Retrieval (ECIR 2015), CEUR-WS.org, CEUR Workshop Proceedings, vol. 1338 (2015)

51. Walsh, D., Clough, P., Foster, J.: User categories for digital cultural heritage. In: Clough P, Goodale P, Agosti M, Lawless S (eds.) Proceedings of the First International Workshop on Accessing Cultural Heritage at Scale Co-located with Joint Conference on Digital Libraries 2016 (JCDL 2016), CEUR-WS.org, CEUR Workshop Proceedings, vol. 1611 (2016) 